\title{
Entrepreneurial Behaviour of Horticultural Farmers in East Khasi Hills and Ri-Bhoi Districts of Meghalaya
}

\author{
Cordilia Kharlukhi* and Kaushal Kumar Jha \\ Department of Agricultural Extension, Nagaland University: SASRD, \\ Medziphema, Nagaland, India \\ *Corresponding author
}

\section{A B S T R A C T}

\section{Keywords}

Horticultural,

Entrepreneurial behaviour, socioeconomic characteristics

Article Info

\section{Accepted:}

18 March 2021 Available Online: 10 April 2021
The study was carried out to examine the socio-economic characteristics of the respondents and factors influencing entrepreneurial behaviour. Ex-post facto research design was followed. The study was conducted purposively in East Khasi Hills and Ri-bhoi districts. Two C\&RD blocks from each district were selected purposively. Further, eight villages were selected purposively where twenty respondents were randomly selected from each., village. Hence, a total sample of 160 respondents for the present study was selected. The findings of the study revealed that majority of the respondents were middle aged (35-55 years) and were male. Most respondents were involved in farming and had medium sized family ranging from 4-10 members. Majority had education up to high school level, had marginal size of total land holding and most respondents cultivating different horticultural crops had marginal size of total land holding. Highest mean annual income of farmers from all sources was found Rs 186900 whereas highest mean annual income of the selected farmers from selected horticultural crops was found to be highest among strawberry growers (Rs 130375). Most of the respondents; possessed medium level; of information source utilization, medium level; of extension contact. Majority had medium level of social participation; scientific orientation, farm experience, knowledge level, adoption level. Most had favourable attitude towards improved practices. Majority of the respondents had medium level of entrepreneurial behaviour. Independent variables: education, extension contact, scientific orientation, knowledge, sex, annual income, income from the selected enterprises, information sources utilization, social participation and attitude exhibited positive and significant correlation with the entrepreneurial behaviour of the respondents. The study recommends organization of trainings, exposure visits, demonstration, awareness, exhibitions to motivate farmers for undertaking entrepreneurial ventures so as to enhance the socio-economic wellbeing of the farmers. 


\section{Introduction}

Entrepreneurship is a formation of humanbehavior. It is essential for widening and management of the society. Normally, entrepreneur is regarded as a person who organizes, initiates activities; direct the event of business component incorporating the element of goods and services from production to supply chain. Entrepreneurial behaviour can be attributed as the change in knowledge, skills and attitude of entrepreneurs in the enterprise they have taken up (Kumar and Poonam, 2019). India, constitute a significant portion of horticultural crops to the total agricultural produce. It distributes about 28 percent of Gross Domestic Product (GDP) and amount the total exports of agricultural commodities for 37 percent from India. About 58 percent of the total population in India depends on agriculture and allied activities (Agriculture in India, 2020). The second largest producer of fruits and vegetables in the world is India, after China.

There is a vast possibility for horizontal and vertical prosperity for horticulture in Northeast region. Horticultural crops amount about 18.60 percent of cultivated area at present. The portion is maximum in Sikkim then comes Manipur, Arunachal Pradesh, Meghalaya, Tripura, Mizoram, Assam and Nagaland (De, 2017).

Meghalaya is a hilly state in northeastern India. Approximately, 3,42,885 ha is the net cropped area or the geographical area of $15.28 \%$. The variation of altitude, soil and climate conditions provides ample scope for growing a large variety of fruits and vegetables. The maximum area among the fruit crops is under pineapple (9.5 thousand ha) then citrus (8.2 thousand ha) and banana (6.2 thousand ha). Meghalaya has second largest acreage of potato (20.8 thousand ha) after Assam.
Farmers cultivating horticultural crops have high chances to become entrepreneurs but due to some constraints such as non-availability of seeds at reasonable price, lack of infrastructure, poor transportation, poor market linkages and lack of awareness, they are not able to achieve much growth. Farmersentrepreneurs need to increase their managerial ability to meet the demands of increasing complexity. If farmers are put up with appropriate trainings and technological know-how and also enterprises are established for marketing aspects, the horticultural crops have the potential to enhance employment and upgrade trade and commerce. Therefore, keeping in view the following issues, the present study shall make an endeavour to fill some of the gaps in the area of entrepreneurship development and to examined the status of horticultural production and marketing of the promising crops in Meghalaya among the farmers with the following

The main objectives include to study the socio-economic characteristics of the respondents cultivating horticultural crops and to examine the entrepreneurial behaviour of the selected respondents and the relationship of selected independent variables in influencing their entrepreneurial behaviour.

\section{Materials and Methods}

For the present study, Ex-post facto research design was used. It's a research method in which groups with qualities that already exist are compared on some dependent variable. The present study was conducted in the state of Meghalaya.

The present study was conducted purposively in East Khasi Hills and Ri-Bhoi districts as East Khasi Hills districts have the highest production in potato and cabbage whereas $\mathrm{Ri}$ Bhoi districts leads in the production of ginger 
and strawberry. Therefore, these two districts were purposively selected for the present study.

There are 8 Community and Rural Development (C\&RD) blocks in East Khasi Hills district out of which two blocks namely Mawryngkneng and Khatarshnong were selected purposively for the present study as these blocks consists of maximum numbers of farmers with respect to the crops selected for study. Also, there are 4 C\&RD blocks in $\mathrm{Ri}$ Bhoi district out of which two blocks namely Umsning and Bhoirymbong C\&RD block has also been selected purposively for this study as these blocks also consists of maximum numbers of farmers with respect to the crops selected for study.

From each of the selected C\&RD blocks, two villages were selected randomly. Smit and Umphrup village were selected for cabbage farmers; Wahstew and Synrangsohnoh village were selected for potato farmers, Sohliya and Dewlieh village for strawberry and Itsopair and Mynri village for ginger. The following villages were selected as most of the farmers are engaged in cultivating the selected crops. Thus, a total of eight villages were randomly selected for the present study. Out of these, twenty respondents have been drawn randomly from each village. Thus, a sample of 160 respondents was selected for the present study.

The selected independent variables included Age, Sex, Occupation, Family size, Educational status, Size of land holding, Annual Income, Information sources utilization, Extension contact, Social participation, Scientific orientation, Experience in cultivation, Knowledge level, Adoption level, Attitude towards improved cultivation. Entrepreneurial behaviour of horticultural farmers cultivating horticultural farmers was selected as dependent variables. The primary data was collected by conducting personal interview with the support of a personal-pre-tested structured-schedule, construct for this purpose. The secondary data and related information were collected from concerned department, various publications, journals, magazines relevant text books, internet sources etc. The data collected from the respondents were scored, tabulated and analyzed to calculate frequency, percentage, mean, standard deviation and correlation.

\section{Results and Discussion}

Socio-economic characteristics of the respondents cultivating horticultural crops

The findings in Table 1 revealed that majority $(63.75 \%)$ of the respondents cultivating the different horticultural crops were middle aged (35-55 years) and (54.38\%) of the respondents were male. The finding was in accordance with the findings of Jha (2012) for age and Phukan et al., (2017) for sex of respondents. 87.5 per cent of the respondents involved in farming and most $(60.62 \%)$ of the respondents had medium sized family ranging from 4-10 members. The finding was in line with the findings of Neupane et al., (2019) for occupation and Somvanshi et al., (2016) for family size of respondents. It was found that majority $(42.5 \%)$ of the respondents had education up to high school level, 58.76 per cent had marginal size of total land holding (less than 2.47 acre) and 80.00 per cent of the respondents cultivating different horticultural crops had marginal size of total land holding (less than 2.47 acre).

The finding was in accordance with the findings of Boruah et al., (2015) for education. It also indicates that highest mean annual income from all sources was found in case of strawberry growers (Rs 186900) and the overall mean annual income from all sources was found to be Rs 122931.875 whereas highest mean annual income of the selected farmers from selected horticultural crop was 
found to be highest among strawberry growers (Rs 130375) and overall mean annual income of the selected farmers from selected horticultural crop was found to be Rs 84975.5. It was revealed that majority $(68.13 \%)$ of the respondents had medium level of information source utilization, $(81.88 \%)$ extension contact, $(71.25 \%)$ social participation; scientific orientation $(75.00 \%)$ and farm experience $(74.38 \%)$. It was also found that majority $(60.63 \%)$ of the respondents had medium level of knowledge and Knowledge Index (KI) was found to be 76.97 respectively. The finding was in line with the findings of Prashanth et al., (2018) for information source utilization, Yetwakar and Dnyaneshwar (2018) for extension contact and social participation, Chouhan et al., (2018) for scientific orientation, Prashanth et al., (2018) for farm experience and Nasrin et al., (2017) for knowledge.

It also revealed that majority $(77.5 \%)$ of the respondents had medium level of adoption and Adoption Index (AI) was found to be 66.89 respectively. Most (70.63\%) of the respondents had favorable attitude towards improved practices and Attitude Index was found to be 60.30 respectively. The finding was in accordance with the findings of Chigadolli et al., (2018) for adoption and Prodhan et al., (2017) for attitude of respondents.

Entrepreneurial behaviour of the selected respondents and the relationship of selected independent variables in influencing their entrepreneurial behaviour

It was revealed from Table 2that majority $(70.00 \%)$ of the respondents growing the different horticultural crops had medium level of entrepreneurial behaviour. The finding was in line with the findings of Boruah et al., (2015). Entrepreneurial Index (EI) was found to be 41.72. Based on the pattern of entrepreneurial behaviour of different horticultural growers had with the different dimensions, it was observed from Table 3 that production orientation had the highest with mean score 9.95 followed by marketing orientation, achievement motivation, management orientation, innovativeness and risk orientation with mean score 9.89, 9.71, $9.48,9.22$ and 8.5 respectively.

Table 4 revealed that independent variables viz., education, extension contact, scientific orientation and knowledge exhibit positive and significant correlation with the entrepreneurial behaviour of the respondents at $1 \%$ level of probability. Also, independent variables sex, annual income, income from the selected enterprises, information sources utilization, social participation and attitude exhibit significant and positive correlation with the entrepreneurial behaviour of respondents at 5\% level of probability. Thus, the variables found to be significant were associated in influencing the entrepreneurial behaviour of the horticultural farmers.

Majority of the respondents cultivating the different horticultural crops were middle aged (35-55 years) in which most of the respondents were male. Majority of the respondents were involved in farming and most had medium sized family ranging from 4-10 members. It was found that majority of the respondents had education up to high school level. In case of size of total land holding most had marginal (less than 2.47 acre) whereas respondents cultivating different horticultural crops, most had marginal size of total land holding (less than 2.47 acre). However, overall mean annual income from all sources was found to be Rs 122931.875 and overall mean annual income from the selected crops was found to be Rs 87225 . It was observed that majority of the respondents had medium level of information source utilization. 
Table.1 Distribution of Respondents based on Socio-economic characteristics of the respondents cultivating horticultural crops.

\begin{tabular}{|c|c|c|}
\hline & & $\mathrm{N}=16$ \\
\hline Attributes & Category & Percentage \\
\hline \multirow{3}{*}{ Age } & Young (<35 years) & 16.87 \\
\hline & Middle (35-55 years) & 63.75 \\
\hline & Old $(>55$ years $)$ & 19.38 \\
\hline \multirow{2}{*}{ Sex } & Male & 54.38 \\
\hline & Female & 45.62 \\
\hline \multirow{3}{*}{ Occupation } & Farming & 87.5 \\
\hline & Employed & 2.5 \\
\hline & Others & 10.00 \\
\hline \multirow{3}{*}{ Family size } & Small (<4 members) & 16.87 \\
\hline & Medium (4 - 10 members) & 60.62 \\
\hline & Large (>10 members) & 22.5 \\
\hline \multirow{6}{*}{ Education } & Illiterate & 10.00 \\
\hline & Primary & 22.5 \\
\hline & Middle school & 16.25 \\
\hline & High School & 42.5 \\
\hline & P.U & 6.25 \\
\hline & Graduate $\&$ above & 2.5 \\
\hline \multirow{4}{*}{ Total land holding } & Marginal $(<2.47$ acre $)$ & 58.76 \\
\hline & Small (2.47-4.94 acre) & 33.12 \\
\hline & Medium (4.95-9.88 acre) & $(5.6)$ \\
\hline & Large (>9.88 acre) & $(2.5)$ \\
\hline \multirow{4}{*}{$\begin{array}{l}\text { Land holding under horticultural } \\
\text { crops }\end{array}$} & Marginal (<2.47 acre) & 80.00 \\
\hline & Small (2.47-4.94 acre) & 18.76 \\
\hline & Medium (4.95-9.88 acre) & 0.62 \\
\hline & Large (>9.88 acre) & 0.62 \\
\hline \multirow{3}{*}{$\begin{array}{c}\text { Level of information sources } \\
\text { utilized }\end{array}$} & Low $(<6.88)$ & 16.25 \\
\hline & Medium (6.88-12.94) & 68.13 \\
\hline & High $(>12.94)$ & 15.62 \\
\hline \multirow{3}{*}{ Level of extension contact } & Low $(<0.76)$ & 5.00 \\
\hline & Medium (0.76-3.34) & 81.88 \\
\hline & High $(>3.34)$ & 13.12 \\
\hline \multirow{3}{*}{ Level of social participation } & Low $(<0.57)$ & 20.00 \\
\hline & Medium (0.57-2.39) & 71.25 \\
\hline & High $(>2.39)$ & 8.75 \\
\hline \multirow{3}{*}{$\begin{array}{c}\text { Level of } \\
\text { Scientific Orientation }\end{array}$} & Low $(<12.82)$ & 11.25 \\
\hline & Medium (12.82-18.1) & 75.00 \\
\hline & High $(>18.1)$ & 13.75 \\
\hline \multirow{3}{*}{ Level of farm experience } & Low (<4.09 years) & 10.62 \\
\hline & Medium (4.09-18.81 years) & 74.38 \\
\hline & High (>18.81 years) & 15.00 \\
\hline \multirow{4}{*}{ Level of overall knowledge } & Low $(<9.04)$ & 26.25 \\
\hline & Medium (9.04-12.12) & 60.63 \\
\hline & High $(>12.12)$ & 13.12 \\
\hline & Knowledge Index (KI) & 76.97 \\
\hline \multirow{3}{*}{ Level of overall adoption } & Low $(<15.76)$ & 8.75 \\
\hline & Medium (15.76-21) & $\mathbf{7 7 . 5}$ \\
\hline & High $(>21)$ & 13.75 \\
\hline
\end{tabular}




\begin{tabular}{|c|c|c|}
\hline & Adoption Index (AI) & 66.89 \\
\hline \multirow{4}{*}{ Level of attitude } & Less favorable $(<12.69)$ & 13.75 \\
\hline & Favorable (12.69-21.07) & 70.63 \\
\hline & More favorable (>21.07) & 15.62 \\
\hline & Attitude Index & 60.30 \\
\hline Attributes & Category & Income (₹ ) \\
\hline $\begin{array}{c}\text { Mean annual income from all } \\
\text { sources (₹) }\end{array}$ & Mean annual income (₹) & $₹ 122931.875$ \\
\hline $\begin{array}{l}\text { Annual income from horticultural } \\
\operatorname{crops}(₹)\end{array}$ & Mean annual income (₹) & ₹ 84975.5 \\
\hline
\end{tabular}

Table.2 Distribution of respondents based on overall entrepreneurial behavior

\begin{tabular}{|c|c|c|}
\hline Attributes & Category & Percentage \\
\hline \multirow{3}{*}{ Level of entrepreneurship } & Low $(<48.61)$ & 13.75 \\
\cline { 2 - 3 } & Medium (Between 48.61-64.87) & $\mathbf{7 0 . 0 0}$ \\
\cline { 2 - 3 } & High $(>64.87)$ & 16.25 \\
\cline { 2 - 3 } & Entrepreneurial Index (EI) & 41.72 \\
\hline
\end{tabular}

Table.3 Distribution of respondents based on the dimensions of entrepreneurial behavior

\begin{tabular}{|c|c|c|}
\hline Dimensions & Mean \& SD & Rank \\
\hline Production orientation & $9.95(1.80)$ & I \\
\hline Marketing orientation & $9.89(2.84)$ & II \\
\hline Achievement motivation & $9.71(2.2)$ & III \\
\hline Management orientation & $9.48(2.05)$ & IV \\
\hline Innovativeness & $9.22(2.27)$ & V \\
\hline Risk orientation & $8.5(2.13)$ & VI \\
\hline
\end{tabular}

Table.4 Correlation between independent variables and entrepreneurial behaviour of the respondents

\begin{tabular}{|c|c|}
\hline Independent variables & Coefficient of correlation (r) \\
\hline Age & $0.087^{\mathrm{NS}}$ \\
Sex & $0.187^{*}$ \\
Occupation & $0.004^{\mathrm{NS}}$ \\
Family size & $-0.045^{\mathrm{NS}}$ \\
Education & $0.231^{* *}$ \\
Size of land holding & $-0.045^{\mathrm{NS}}$ \\
Annual income & $0.193^{*}$ \\
Income from the selected enterprises & $0.166^{*}$ \\
Information sources utilization & $0.165^{*}$ \\
Extension contact & $0.222^{* *}$ \\
Social participation & $0.188^{*}$ \\
Scientific orientation & $0.234^{* *}$ \\
Experience in cultivation & $0.100^{\mathrm{NS}}$ \\
Knowledge & $0.212^{* *}$ \\
Adoption & $-0.047^{\mathrm{NS}}$ \\
Attitude & $0.179^{*}$ \\
\hline
\end{tabular}

**significant at $1 \%$ level of probability

* significant at $5 \%$ level of probability

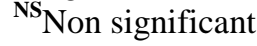


It also revealed that majority of the respondents had medium level of extension contact. Also, it revealed that most of the respondents possessed medium-level of social participation; scientific; orientation and farm experience. It was also found that majority of the respondents had medium level of knowledge and medium level of adoption and majority of the respondents had favorable attitude towards improved practices.

Majority of the respondents growing the different horticultural crops had medium level of entrepreneurial behaviour. Based on the pattern of entrepreneurial behaviour of different horticultural growers had with the different dimensions, it was observed that production orientation had the highest with mean score 9.95 .

Independent variables viz., education, extension contact, scientific orientation and knowledge exhibit positive and significant correlation with the entrepreneurial behaviour of the respondents at $1 \%$ level of probability.

Also, independent variables viz., sex, annual income, income from the selected enterprises, information sources utilization, social participation and attitude exhibit significant and positive correlation with the entrepreneurial behaviour of the respondents at $5 \%$ level of probability.

Thus, the variables found to be important in influencing the entrepreneurial behaviour of the horticultural farmers.

\section{Acknowledgement}

The work was supported by the Department of Extension, School of Agricultural Sciences and Rural Development, Medziphema, India. I am grateful to Dr. K. K. Jha for his assistance and guidance in completion of this research work.

\section{References}

Anonymous. 2020. Agriculture in India. Information about Indian agriculture and its importance. Accessed on $4^{\text {th }}$ September 2020.

Boruah, R., Borua, S., Deka, C.R. and Borah, D. 2015. Entrepreneurial behaviour of tribal Winter Vegetable Growers in Jorhat District of Assam.International Research Journal of Extension Education.15(1): 65-69.

Chigadolli, M., Krishnamurthy, B. and Mallikarjuna Gowda, A. P. 2018. A study on Knowledge of turmeric growers about improved cultivation practices in Belagavi district of Karnataka. International Journal of Agricultural Sciences. 10(22): 75457548 .

Chouhan, M. N. 2018. Knowledge level of tribal farmers regarding okra production technology in South Gujarat. Indian Research Journal of Extension Education. 18(2): 62-65.

De, C. L. 2017. Horticulture scenario in Northeast Region of India. International Journal of Agricultural Science and Research.7(2): 243-254.

Jha K K. 2012. Entrepreneurial behaviour of pineapple growers.Indian Research Journalof Extension Education Special Issue (1): 142-145.

Kumar, A. and Poonam. 2019. Entrepreneurial attributes of vegetable growers: A study in Baloda district of Chattisgarh. International Journal of Chemical Studies. 6: 22-25

Nasrin, M., Borua, S., Borua, R. and Deka, B. 2017. Knowledge level of farmers on recommended cultivation practices of off-season vegetables crops under low cost polyhouse technology in Assam. Asian Journal of Agricultural Extension, Economics \& Sociology. 21(4): 1-6. 
Neupane, J., Ghimire, S., Chalise, D. P. andDevkota, D. 2019. Socio-economic analysis of ginger production in Surkhet district of Nepal. Acta Scientific Agriculture. 3(11): 28-33.

Phukan, P., Lepeha, B., Avasthe, R. and Singh, J. N. 2017. Socio-economic characteristics and constraints faced by Horticultural of East Sikkim. Journal of Krishi Vigyan. 6(1): 175-179.

Prashanth, R., Jahanara and Bose, D. K. 2018. Adoption behaviour of farmers regarding improved cultivation practices of pomegranate crop in Chitradurga district of Karnataka. International Journal of Research Culture Society. 2(5): 163-165.
Prodhan, AZM. S., Sarker, MNI, Sultana, A. and Islam, MS. 2017. Knowledge, adoption and attitude on banana cultivation technology of the banana growers of Bangladesh. International Journal of Horticultural Sciences and Ornamental Plants. 3(1): 047-052.

Somvanshi, R. M., Deshmukh, A. N., Mokhale, S. U. and Godase, S. K. 2016. Entrepreneurial behaviour of vegetable growers. Agriculture Update. 11(3): 239-241.

Yetwakar and Dnyaneshwar, H. 2018. Entrepreneurial behaviour of garlic growers. M.Sc (Ag) Thesis, Dr.Punjabrao Deshmukh Krishi Vidyapeeth, Akola.

\section{How to cite this article:}

Cordilia Kharlukhi and Kaushal Kumar Jha. 2021. Entrepreneurial Behaviour of Horticultural Farmers in East Khasi Hills and Ri-Bhoi Districts of Meghalaya. Int.J.Curr.Microbiol.App.Sci. 10(04): 575-582. doi: https://doi.org/10.20546/ijcmas.2021.1004.057 